\title{
PERBEDAAN KETERAMPILAN PERTOLONGAN PERSALINAN NORMAL ANTARA MEDIA MODEL DAN MEDIA VIDEO PADA MAHASISWA SEMESTER TIGA DI PRODI DIII KEBIDANAN STIKES MUHAMMADIYAH LAMONGAN TAHUN 2016
}

\author{
Kustini \\ *Program Studi Bidan D III Kebidanan Universitas Islam Lamongan
}

\begin{abstract}
Lack of midwives, knowledge and skills leads to low performance and quality of service. The effort can be done is increase the knowledge and skill, reality shows that most learning using only one kind of media and one time demonstration. The issue is using media is minimize exactly on practical helping labor and laboratories learning in STIKES Muhamadiyah Lamongan.

The purpose of this study is to determine the difference skill helping normally labor using model and Video in STIKES Muhammadiyah Lamongan 2016. This research is comparative analytical study with cross sectional approach. The population is 100 students and the sample of 80 student, uses simple random sampling. Independent variable is the use of model and video, dependent variable is skill of helping normally labor.

The results is more than a majority respondent who use model is able to doing skill helping normally labor, that 29 respondent $(72,5 \%)$, and more than majority proficient doing skill helping normally labor, that 24 respondent $(60 \%)$.

Analysis using SPP 16.0 with Mann Whitney test $\alpha=0,05, p=0.000$ so $p<\alpha$, concluded that there are difference skill helping normally labor between using model and video media.

Seeing these results it is necessary to use a medium that is thought to correspond to the learning objectives that lead to learning motivation so that skills become better destination
\end{abstract}

Keywords : media , models, videos , normal delivery

\section{Pendahuluan}

Perkembangan jaman yang semakin modern terutama pada era globalisasi seperti sekarang ini menuntut adanya sumber daya manusia yang berkualitas tinggi. Peningkatan kualitas sumber daya manusia merupakan prasyarat mutlak untuk mencapai tujuan pembangunan. Salah satu wahana untuk meningkatkan kualitas sumber daya manusia tersebut adalah pendidikan. Upaya dalam meningkatkan kualitas proses dan hasil belajar sebagai bagian dari peningkatan kualitas pendidikan dapat dilakukan melalui system penilaian (Sudjana, 2008)

Upaya memperbaiki dan meningkatkan mutu pendidikan seakan tidak pernah berhenti. Banyak agenda reformasi yang telah, sedang, dan akan dilaksanakan. Beragam program inovatif ikut serta memeriahkan reformasi pendidikan. Reformasi pendidikan tidak cukup hanya dengan perubahan dalam sector kurikulum. Pembaharuan kurikulum akan lebih bermakna bila diikuti oleh perubahan praktik pembelajaran di dalam maupun di luar kelas. Indikator pembaruan kurikulum ditunjukkan dengan adanya perubahan pola kegiatan pembelajaran, pemilihan media pendidikan, penentuan pola penilaian yang menentukan hasil pendidikan. (Majid, 2008).

Berdasarkan hasil investigasi kualitas secara tepat (Quick Investigation of Quality) yang dilakukan di Provinsi Jawa Tengah dan Jawa Timur, terungkap bahwa hampir sebagian besar $(80 \%)$ 
penolong persalinan yang bekerja di fasilitas kesehatan tidak mampu melaksanakan asuhan persalinan sesuai dengan standar yang diinginkan. Tidak tersedianya standar asuhan, terbatasnya pengetahuan dan ketrampilan yang dibutuhkan, dan kurangnya kepatuhan petugas terhadap standar menyebabkan rendahnya kinerja dan kualitas pelayanan. Salah satu upaya yang dapat dilakukan adalah meningkatkan pengetahuan dan ketrampilan petugas kesehatan dalam menolong persalinan. (JNPK-KR, 2008)

Praktikum pertolongan persalinan normal merupakan salah satu praktikum wajib yang harus dilakukan oleh mahasiswa kebidanan. Praktikum tersebut masuk dalam salah satu mata uji dalam ujian tahap. Dari hasil survey awal yang dilakukan di Prodi DIII Kebidanan STIKES Muhammadiyah Lamongan menunjukkan bahwa semua dosen pembimbing memanfaatkan media model (phantoom) dalam proses bimbingan pertolongan persalinan normal dengan metode pembelajaran demonstrasi di laboratorium. Demonstrasi dilakukan satu kali kemudian mahasiswa mencoba untuk melakukan per individu. Berdasarkan hasil wawancara dengan salah satu dosen penguji ketrampilan pertolongan persalinan normal, didapatkan data bahwa dari 30 mahasiswa yang diuji terdapat 10 mahasiswa $(33 \%)$ yang harus mengalami remidi atau ujian ulang. Dari kenyataan tersebut dapat diindikasikan bahwa ketrampilan siswa belum cukup optimal. Berdasarkan hasil wawancara terhadap 10 mahasiswa yang telah melaksanakan bimbingan pertolongan persalinan dengan metode demonstrasi menggunakan media model di laboratorium, 8 mahasiswa ( $80 \%$ ) mengatakan kurang puas dengan metode tersebut, mereka beralasan kesulitan mempelajari apa yang telah diajarkan ketika mereka belajar mandiri di rumah. Bahkan mereka lupa dengan praktikum persalinan normal setelah dilakukan ujian.

Keberhasilan studi mahasiswa dipengaruhi oleh banyak faktor yang berasal baik dari dalam maupun dari luar mahasiswa. Faktor dari luar misalnya fasilitas belajar (media pembelajaran), cara mengajar dosen (metode pembelajaran), system pemberian umpan balik. Faktor dari dalam mahasiswa mencakup kecerdasan, strategi belajar, motivasi. Salah satu faktor yang dapat mempengaruhi belajar siswa adalah metode pembelajaran. Tidak semua metode pembelajaran sesuai untuk digunakan dalam mencapai tujuan pembelajaran. Metode pembelajaran berfungsi sebagai cara dalam menyajikan (menguraikan, memberi contoh, memberi latihan) isi pelajaran kepada mahasiswa untuk mencapai tujuan tertentu. Seorang guru dalam menyampaikan materi perlu memilih metode mana yang sesuai dengan keadaan kelas atau siswa sehingga siswa merasa tertarik untuk mengikuti pelajaran yang diajarkan. Dengan variasi metode dapat meningkatkan kegiatan belajar siswa (Slameto, 2003).

Selain metode pembelajaran, factor lain yang mempengaruhi hasil belajar adalah media pembelajaran. Media pembelajaran harus dimanfaatkan oleh dosen dalam pembelajaran. Namun pada kenyataanya media pembelajaran terabaikan dengan berbagai alasan seperti terbatasnya waktu untuk membuat persiapan mengajar, sulit untuk mencari media yang tepat, biaya tidak tersedia, atau alasan lainnya. Alasan tersebut sebenarnya tidak perlu muncul karena terdapat banyak jenis media yang dapat digunakan, disesuaikan dengan kondisi waktu, keuangan, maupun materi yang akan disampaikan.

Media merupakan sesuatu yang bersifat menyalurkan pesan dan dapat merangsang pikiran, perasaan, dan kemauan audiens (siswa) sehingga dapat mendorong terjadinya proses belajar. Penggunaan media secara kreatif akan memungkinkan belajar lebih baik. Pada hakikatnya proses belajar mengajar adalah proses komunikasi. Kegiatan belajar mengajar di kelas merupakan suatu dunia 
komunikasi tersendiri dimana dosen dan siswa bertukar pikiran untuk mengembangkan ide dan pengertian. Tanpa adanya media dalam komunikasi sering timbul dan terjadi penyimpangan sehingga komunikasi tidak efektif dan efisien, antara lain disebabkan oleh adanya kecenderungan verbalisme, ketidaksiapan siswa, kurangnya minat dan kegairahan, dan lain sebagainya. selain itu tanpa adanya media akan menurunkan motivasi belajar, mengurangi daya serap dan pemahaman belajar siswa. Salah satu usaha untuk mengatasi keadaan demikian ialah penggunaan media secara terintegrasi dalam proses belajar mengajar sehingga ketidakjelasan dari bahan yang disampaikan dapat dibantu dengan menghadirkan media sebagai perantara. (Wahit Iqbal Mubarak, 2007)

\section{Metode Penelitian}

Rancangan yang digunakan dalam penelitin ini dijelaskan berdasarkan berbagai perspektif yaitu Berdasarkan lingkup penelitian termasuk jenis penelitian analitik, Berdasarkan tempat penelitian termasuk jenis penelitian lapangan, Berdasarkan waktu pengumpulan data termasuk jenis rancangan yang digunakan cross sectional, Berdasarkan ada tidaknya perlakuan termasuk jenis penelitian quasy eksperimen, Berdasarkan cara pengumpulan data termasuk jenis survey, Berdasarkan tujuan penelitian termasuk jenis analitik komparatif, Berdasarkan sumber data termasuk jenis primer.

Populasi pada penelitian ini adalah seluruh mahasiswa semester tiga Program Studi DIII Kebidanan STIKES Muhammadiyah Lamongan sebanyak 100 mahasiswa. Penentuan besar sampel didasarkan pada rumus :

$$
\mathbf{n}=\frac{\mathbf{N}}{1+\mathbf{N}(\alpha)^{2}}+\frac{100}{1+100\left([0,05) \rrbracket^{2}\right.}=80
$$

Sampel yang gunakan pada penelitian ini sebanyak 80 mahasiswa dengan pembagian 40 mahasiswa menggunakan media model dan 40 mahasiswa menggunakan media video. Sampling yang digunakan dalam penelitian ini adalah Simple Random Sampling atau pengambilan sampel acak sederhana.

Data yang terkumpul di analisa dengan menggunakan metode deskriptif yaitu dengan rumus prosentase. Setelah data terkumpul dari pengisian checklist kemudian diberikan skor pada setiap tindakan responden, kemudian hasilnya dimasukkan dalam kriteria standar penelitian dan dikategorikan awal (0-58), mampu (59-116), mahir (117-174). Setelah dilakukan scoring kemudian data dikelompokkan kedalam suatu tabel sesuai kriteria yang telah ditentukan. Kemudian data yang sudah dikelompokkan dan di prosentasekan dimasukkan kedalam tabel kemudian di analisis.

Untuk menganalisis perbedaan ketrampilan pertolongan persalinan normal antara media model dengan media video menggunakan uji statistic Man whitney dikarenakan variabel berskala ordinal. Jenis sampel adalah sampel bebas. Kemudian data dimasukkan dalam computer dengan menggunakan program SPSS dengan $\alpha=0,05$. Dasar pengambilan keputusan adalah $\mathrm{H} 0$ ditolak apabila $\mathrm{p}$ value $<\alpha$.

\section{Hasil Penelitian}

Tabel 1 Distribusi Frekuensi Umur Responden Berdasarkan media model di STIKES Muhammadiyah Lamongan Tahun 2016

\begin{tabular}{clcc}
\hline No & \multicolumn{1}{c}{ Umur } & $\begin{array}{r}\text { Frekue } \\
\text { nsi }\end{array}$ & $\begin{array}{c}\text { Prosentase } \\
(\%)\end{array}$ \\
\hline 1 & Dewasa awal & 19 & 47,5 \\
2. & $\begin{array}{l}\text { (19-20 tahun) } \\
\text { Dewasa (20-24 } \\
\text { tahun) }\end{array}$ & 21 & 52,5 \\
\hline \multicolumn{1}{c}{ Total } & 40 & 100 \\
\hline
\end{tabular}

Sumber : Data Primer Tahun 2016

Berdasarkan tabel 1 dinterprestasikan bahwa sebagian besar responden berumur dewasa yaitu 21 responden $(52,5 \%)$ 
Tabel2 Distribusi Frekuensi Umur Responden Berdasarkan media video di STIKES Muhammadiyah Lamongan Tahun 2016

\begin{tabular}{clcc}
\hline No & \multicolumn{1}{c}{ Umur } & Frekuensi & $\begin{array}{c}\text { Prosentase } \\
(\%)\end{array}$ \\
\hline 1 & Dewasa & 29 & 72,5 \\
& awal (19-20 & 11 & 27,5 \\
& $\begin{array}{l}\text { tahun) } \\
\text { 2. }\end{array}$ & & \\
& $\begin{array}{l}\text { Dewasa (20- } \\
\text { 24 tahun) }\end{array}$ & & \\
\hline \multicolumn{1}{c}{ Total } & 40 & 100 \\
\hline
\end{tabular}

Sumber : Data Primer Tahun 2016

Berdasarkan tabel 2 dinterprestasikan bahwa sebagian besar responden berumur dewasa awal yaitu 29 responden $(72,5 \%)$

Tabel 3 Distribusi Frekuensi Latar Belakang Pendidikan Responden Berdasarkan media model di STIKES Muhammadiyah Lamongan Tahun 2016

\begin{tabular}{llcc}
\hline $\begin{array}{c}\text { N } \\
\text { o }\end{array}$ & $\begin{array}{c}\text { Latar Belakang } \\
\text { Pendidikan }\end{array}$ & Frekuensi & $\begin{array}{c}\text { Prosentase } \\
(\%)\end{array}$ \\
\hline 1 & SMA & 23 & 57,5 \\
2 & SMK & 3 & 7,5 \\
3 & MA & 14 & 35 \\
\hline & Total & 40 & 100 \\
\hline
\end{tabular}

Sumber : Data Primer Tahun 2016

Berdasarkan tabel 3 diintrepretasikan bahwa lebih dari sebagian responden mempunyai latar belakang pendidikan SMA yaitu 23 responden $(57,5 \%)$.

Tabel 4 Distribusi Frekuensi Latar Belakang Pendidikan Responden Berdasarkan media video di STIKES Muhammadiyah Lamongan Tahun 2016

\begin{tabular}{cccc}
\hline $\mathrm{N}$ & $\begin{array}{c}\text { Latar } \\
\text { Belakang }\end{array}$ & Frekuensi & $\begin{array}{c}\text { Prosentase } \\
(\%)\end{array}$ \\
& Pendidikan & & \\
\hline 1 & SMA & 20 & 50 \\
2 & SMK & 4 & 10 \\
3 & MA & 16 & 40 \\
\hline & Total & 40 & 100 \\
\hline
\end{tabular}

Sumber : Data Primer Tahun 2016
Berdasarkan tabel 4 diintrepretasikan bahwa lebih dari setengahnya responden mempunyai latar belakang pendidikan SMA yaitu 20 responden (50\%)

Tabel 5 Distribusi Frekuensi Responden Berdasarkan Ketrampilan Pertolongan Persalinan Normal Menggunakan Media Model di STIKES Muhammadiyah Lamongan Tahun 2016

\begin{tabular}{clcc}
\hline No & $\begin{array}{c}\text { Tingkat } \\
\text { Ketrampilan }\end{array}$ & Frekuensi & $\begin{array}{c}\text { Prosentase } \\
\%\end{array}$ \\
\hline 1 & Awal & 1 & 2,5 \\
2 & Mampu & 29 & 72,5 \\
3 & Mahir & 10 & 25 \\
\hline & Total & 40 & 100 \\
\hline
\end{tabular}

Sumber : Data Primer Tahun 2016

Berdasarkan tabel 5 diintrepretasikan bahwa lebih dari sebagian responden yang menggunakan media model mampu melakukan ketrampilan pertolongan persalinan normal yaitu 29 responden (72, $5 \%$ )

Tabel6 Distribusi Frekuensi Responden Berdasarkan Ketrampilan Pertolongan Persalinan Normal Menggunakan Media Video di STIKES Muhammadiyah Lamongan Tahun 2016

\begin{tabular}{clcc}
\hline No & $\begin{array}{c}\text { Tingkat } \\
\text { Ketrampilan }\end{array}$ & Frekuensi & $\begin{array}{c}\text { Prosentase } \\
\%\end{array}$ \\
\hline 1 & Awal & 0 & 0 \\
2 & Mampu & 16 & 40 \\
3 & Mahir & 24 & 60 \\
\hline & Total & 40 & 100
\end{tabular}

Sumber : Data Primer Tahun 2016

Berdasarkan tabel 6 diintrepretasikan bahwa lebih dari sebagian responden mahir melakukan keterangan pertolongan persalinan yaitu 24 responden $(60 \%)$

Tabel 7 Distribusi Frekuensi Responden Berdasarkan Ketrampilan Pertolongan Persalinan Normal Menggunakan Media Model dan 
Video di STIKES Muhammadiyah Lamongan Tahun 2016

berlangsungnya proses pembelajaran. (Wahit Iqbal Mubarak, 2007)

Hasil penelitian menunjukkan bahwa \begin{tabular}{ccccc}
\hline \multirow{2}{*}{ No Media Ketrampilan } & \multicolumn{3}{c}{ Tokegiatan belajar mengajar akan lebih } \\
\cline { 2 - 4 } & Awal $\%$ & Mampu \% Mahir \% & talefektif dan mudah bila dibantu dengan
\end{tabular}

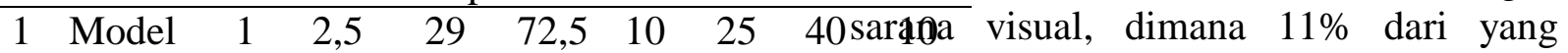

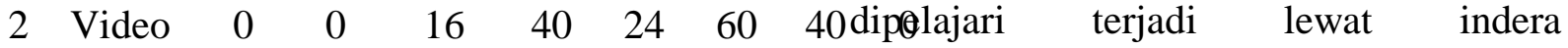
pendengaran, sedangkan $83 \%$ lewat indera perglihatan. Disamping itu dikemukakan

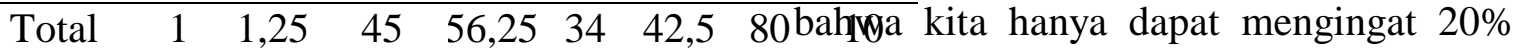
darii apa yang kita dengar namun dapat

Sumber : Data Primer Tahun 2016

Berdasarkan tabel 7 diintrepretasikan bahwa lebih dari sebagian responden yang menggunakan media model mampu melakukan ketrampilan pertolongan persalinan normal yaitu 29 responden $(72$, 5\%) dan sebagian kecil mempunyai ketrampilan awal yaitu 1 responden $(2,5 \%)$. Sedangkan responden yang menggunakan media video lebih dari sebagian mahir melakukan ketrampilan pertolongan persalinan yaitu 24 responden (60\%) dan tidak satupun responden yang mempunyai ketrampilan awal $(0 \%)$

\section{Pembahasan}

\section{Ketrampilan Pertolongan Persalinan Normal Menggunakan Media Model}

Berdasarkan tabel 3 menunjukkan bahwa responden yang menggunakan media model lebih dari sebagian mampu melakukan ketrampilan pertolongan persalinan normal yaitu 29 responden (72, $5 \%$ )

Media model merupakan media visual tiga dimensi yang merupakan representasi dari benda sesungguhnya. Penggunaan media model memungkinkan mahasiswa dapat memusatkan perhatian kepada bagian dalam benda yang sulit didapat pada obyek sebenarnya. Model dapat berukuran lebih besar, lebih kecil atau berukuran sama seperti benda aslinya serta menampilkan wujud yang lengkap dan rinci seperti benda aslinya atau dapat ditampilkan dalam wujud yang lebih disederhanakan untuk mempermudah mengingat $50 \%$ dari apa yang dilihat dan didengar.

Pembelajaran materi pertolongan persalinan normal dengan media model hanya dapat dilakukan dilaboratorium karena jumlah model yang terbatas dan ukuran model yang tidak memungkinkan untuk dibawa kemanamana sehingga mahasiswa tidak mempunyai kesempatan untuk melihat demonstrasi praktek persalinan. Mahasiswa hanya mengingat-ngingat apa yang dilihat sebelumnya apabila mahasiswa menginginkan untuk mempraktekkan maka harus mengharuskan mahasiswa untuk datang ke labolatorium sehingga membutuhkan waktu yang lebih banyak.

\section{Ketrampilan Pertolongan Persalinan Normal Menggunakan Media Video}

Berdasarkan tabel 3 menunjukkan bahwa responden yang menggunakan media video lebih dari sebagian mahir melakukan ketrampilan pertolongan persalinan yaitu 24 responden $(60 \%)$

Dengan menggunakan media, maka proses pembelajaran dapat dilakukan dimana saja dan kapan saja sehingga mahasiswa dapat belajar dimanapun dan kapanpun tanpa tergantung pada keberadaan dosen. Dengan media video memungkinkan mahasiswa belajar secara mandiri. (Briggs dalam Suciati, 2001)

Media video memiliki hampir semua kelebihan yang dimiliki oleh media pembelajaran yang lain. Media video mampu menampilkan gerakan, suara, gambar. Yang lebih penting bahwa media 
video lebih fleksibel dan dapat diputar berulang-ulang sehingga memudahkan peserta didik untuk mempelajari setiap saat.

Pembelajaran ketrampilan pertolongan persalinan normal memerlukan pengamatan dan pemahaman yang baik dalam mengamati tindakan dalam pertolongan persalinan sesuai dengan langkah-langkah yang terstandart dalam cheklist. Dengan menggunakan media video diharapkan mahasiswa mampu mengamati secara detail dan dapat dilakukan berulang-ulang sehingga mahasiswa semakin paham dan pada akhirnya mahir dalam pertolongan persalinan normal.

\section{Perbedaan Ketrampilan Pertolongan Persalinan Normal Menggunakan Media Model dan Media Video}

Berdasarkan hasil analisa menggunakan program SPSS 16,0 dengan uji statistik Mann-Whitney menggunakan $\alpha=0,05$ dan nilai $p=0,000$ sehingga $p<\alpha$ artinya $\mathrm{Ho}$ ditolak dan $\mathrm{H}_{1}$ diterima dapat disimpulkan bahwa terdapat perbedaan ketrampilan pertolongan persalinan normal antara media model dan media video.

Media dalam arti yang terbatas sebagai alat bantu pembelajaran. Hal ini berarti media dapat digunakan sebagai alat bantu yang digunakan untuk memotivasi peserta didik. Dengan menggunakan media diharapkan materi yang diajarkan menjadi lebih jelas, mudah, menarik sehingga menarik peserta didik untuk belajar. (Wahit Iqbal Mubarak, 2007)

Media pembelajaran merupakan bagian yang sangat penting dan tidak terpisahkan dari proses pembelajaran. Dengan adanya perkembangan ilmu dan teknologi, akan semakin mendorong usaha-usaha ke arah pembaharuan dan memanfaatkan hasil teknologi dalam pelaksanaan pembelajaran. Masing-masing media pembelajaran mempunyai kelebihan dan kekurangan. Diantara kelebihan dan kekurangan tersebut, masing-masing media pembelajaran mempunyai daya tarik tersendiri yang dapat memotivasi mahasiswa terhadap apa yang disampaikan. (Slameto, 2003)

Dalam sistem pendidikan nasional rumusan tujuan pendidikan menggunakan klasifikasi hasil belajar dari Benyamin Bloom yang secara garis besar membaginya menjadi tiga ranah yaitu ranah kognitif, afektif dan psikomotoris. Penilaian yang digunakan dalam pertolongan persalinan melalui pengamatan langsung peragaaan ketrampilan klinik pada model anatomi atau klien. Dilaksanakan sesuai langkahlangkah yang diuraikan dalam bentuk daftar tilik penilaian ketrampilan, dan dilaksanakan pada waktu tertentu.

Media model kurang bisa menjangkau kelas yang lebih luas sehingga dibutuhkan kelompok - kelompok kecil dalam pembelajaran ketrampilan pertolongan persalinan normal. Selain itu pembelajaran dengan media model hanya dapat dilakukan di dalam kelas atau laboratorium. Berdasarkan hasil wawancara dengan beberapa mahasiswa mereka mengatakan pembelajaran dengan menggunakan video lebih menarik dan mempermudah dalam belajar karena mahasiswa dapat mengulang kembali dengan melihat rekaman video apabila lupa dengan pembelajaran yang telah diajarkan. Sedangkan apabila hanya dengan menggunakan media model, mahasiswa akan mengingat-ingat kembali apa yang telah diajarkan sehingga secara detail kurang bisa menirukan ketrampilan yang telah diajarkan.

Berdasarkan hasil wawancara diketahui hampir semua mahasiswa mempunyai alat telekomunikasi handphone yang dapat digunakan untuk memindahkan data rekaman video. Sehingga mahasiswa dapat dengan mudah memanfaatkan media video ketika belajar ketrampilan pertolongan persalinan normal. Penggunaan media video memungkinkan mahasiswa dapat mempelajari ketrampilan pertolongan 
persalinan normal dimana saja dan kapan saja.

Berdasarkan usia diketahui bahwa sebagian besar responden berusia $19-20$ tahun. Menurut Hurlock (2000) remaja mempunyai batasan umur 12-20 tahun, dimana merupakan masa peralihan dari masa anak-anak ke masa dewasa. Pada masa remaja, manusia tidak dapat disebut sudah dewasa juga tidak bisa disebut masih anak-anak. Pada masa remaja diketahui sebagai usia yang menimbulkan ketakutan. Sehingga kemungkinan mahasiswa dengan usia remaja akan lebih giat dalam belajar karena adanya perasaan takut atau malu jika tidak mampu untuk melakukan pratikum pertolongan persalinan normal sebagai sebuah tanggung jawab yang harus diselesaikan.

Pada usia remaja merupakan tahap pencapaian kemandirian dan identitas yang sangat menonjol, mereka ingin merasa paling baik diantara lain, pada masa remaja diketahui usia yang menimbulkan ketakutan sehingga kemungkinan mahasiswa akan belajar lebih giat karena adanya perasaan ketakutan dalam praktikum persalinan, sehingga mahasiswa ingin mendapat nilai yang terbaik diantara yang lain, sehingga berusaha keras dapat menyelesaikan

Sedangkan usia dewasa mempunyai batasan umur antara 20- 40 tahun, dimana usia dewasa memiliki sebuah paradigma atau pemikiran yang matang dan jernih dibandingkan usia remaja, serta dapat menganalisis dapat menyimpulkan sebuah keputusan. Bagi mahasiswa yang mempunyai usia dewasa, ketrampilan pertolongan persalinan sampai pada level mampu saja sudah dianggap sebagai pencapaian yang baik karena pada level ini sudah dianggap dapat mencapai tanggung jawabnya tanpa harus berusaha ingin menonjol paling baik diantara teman yang lain.

\section{Kesimpulan}

1. Ketrampilan pertolongan persalinan normal menggunakan media model di
Prodi DIII Kebidanan STIKES

Muhammadiyah Lamongan tahun 2016 Lebih dari sebagian besar responden yang menggunakan media model mampu melakukan ketrampilan pertolongan persalinan normal.

2. Ketrampilan pertolongan persalinan normal menggunakan media video di Prodi DIII Kebidanan STIKES Muhammadiyah Lamongan tahun 2016. Lebih dari sebagian besar responden yang menggunakan media video mahir melakukan ketrampilan pertolongan persalinan.

3. Terdapat perbedaan ketrampilan pertolongan persalinan normal antara media model dan media video di Prodi DIII Kebidanan STIKES Muhammadiyah Lamongan tahun 2016

\section{DAFTAR PUSTAKA}

Arikunto, 2002. Prosedur Penelitian Suatu Pendekatan Praktek. Jakarta : Rineka Cipta

Chandra, Budiman. (2008). Metodologi Penelitian Kesehatan. Jakarta, EGC.

Hasan, I. 2004. Analisis Data Penelitian dengan Statistik. Jakarta: Bumi Aksara

Hikmawati, Isna. 2011. Promosi Kesehatan untuk Kebidanan. Jogjakarta : Nuh Medika

Html://likeendt.blogspot.com. Psikologi perkembangan diakses tanggal 27 Januari 2014

Iqbal Mubarak, Wahit. (2007). Promosi Kesehatan. Yogyakarta, Graha Ilmu.

Jaringan Nasional Pelatihan Klinik Kesehatan Reproduksi (JNPKKR). (2008). Pelatihan Klinik Asuhan Persalinan Normal Asuhan Esensial, Pencegahan dan Penanggulangan Segera 
Komplikasi Persalinan dan Bayi Baru Lahir.

Luknis, Sabri. (2008). Statistik Kesehatan. Jakarta, PT Raja Grafindo Persada.

Majid, Abdul. (2008). Perencanaan Pembelajaran Mengembangkan Standar Kompetensi Guru. Bandung, PT Remaja Rosdakarya.

Notoatmodjo, Soekidjo. (2002). Metodologi Penelitian Kesehatan. Jakarta, Rineka Cipta.

Nazir. (2005) Metode Penelitian Bogor : Galia Indonesia

Suciati, 2001. Teori Belajar dan Motivasi. Jakarta : PAV-PPAI Universitas Terbuka

Sugiono, 2006. Statistik Untuk Penelitian. Bandung : Alfabeta

Supranto, J.2009. Statistik Teori dan Aplikasi. Jakarta : Erlangga

Nursalam. (2003). Konsep \& Penerapan Metodologi Penelitian Ilmu Keperawatan : Pedoman Skripsi, Tesis danInstrumen Penelitian Keperawatan. Jakarta, Salemba Medika.

Slameto. (2003). Belajar dan FaktorFaktor yang Mempengaruhinya. Jakarta, PAU-PPAI Universitas Terbuka00

Sudjana, Nana. (2008). Penilaian Hasil Proses Belajar Mengajar. Bandung, PT Remaja Rosdakarya.

Suparman, M. Atwi. (2005). Desain Instruksional. Jakarta, PAU-PPAI Universitas Terbuka

Zainul Asnawi (2001). Penilaian Hasil Belajar. Jakarta-PAV-PPAI Universitas Terbuka www. Siputro.com/. Tahap Perkembangan Menurut Erikson Hurlock diakses Mei 2013 